TẠP CHÍ KHOA HỌC ĐẠI HỌC TÂN TRÀO

ISSN: 2354 - 1431

http://tckh.daihoctantrao.edu.vn/

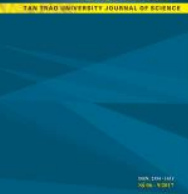

\title{
GIẢI PHÁP KHAI THÁC NGUỒN HỌC LIÊU PHỤC VỤ BẠN ĐỌC TẠI TRƯỜNG ĐẠI HỘC TẦN TRÀO
}

\author{
Lê Kim Anh ${ }^{a^{*}}$ \\ ${ }^{a}$ Truoòng Đại học Tân Trào \\ *Email: lekimanh.86@gmail.com
}

\section{Thông tin bài viết}

Ngày nhận bài:

9/4/2020

Ngày duyệt đăng:

$10 / 6 / 2020$

Tù khóa:

Nguồn hoc liệu, khai thác nguồn học liệu, giải pháp khai thác nguồn hoc liệu.

\section{Tóm tắt}

Hệ thống nguồn học liệu là một bộ phận có giá trị đặc thù trong nguồn tin nội sinh của trường đại học, phản ánh thương hiệu, uy tín của trường đại học. Đối với các trung tâm học liệu hoặc trung tâm thông tin - thư viện của các cơ sở giáo dục đại học thì nguồn học liệu của thư viện hỗ trợ đắc lực cho các hoạt động giảng dạy, học tập, nghiên cứu khoa học của bạn đọc. Bài viết này phân tích thực trạng và đưa ra một số giải pháp khai thác nguồn học liệu phục vụ bạn đọc tại Trường Đại học Tân Trào.

\section{Mở đầu}

Vào đầu những năm 1990, thuật ngũ̃ courseware, tiếng Việt là học liệu ra đời và được sử dụng trong rất nhiều tài liệu khoa học. Thuật ngữ gốc được tạo thành từ sự kết hợp 2 thuật ngữ nguyên thủy là course và software, phản ánh các loại tài liệu được sinh viên sử dụng trong quá trình học ở trường đại học, do người dạy xác định, lựa chọn và thường được bao gói dưới dạng số để khai thác được qua máy tính. Liền sau đó là sự xuất hiện của Open Course Ware (OCW) - học liệu mở, thuật ngữ được sử dụng để chỉ các tài liệu giảng dạy, giáo trình do các trường đại học tạo nên và có thể được chia sẻ tự do trong cộng đồng sử dụng Interrnet.

Xét về thành phần, hệ thống nguồn học liệu bao gồm: đề cương bài giảng, các tài liệu hướng dẫn, kiểm tra, bài tập, giáo trình, chuyên khảo, bài báo khoa học, luận án.... có nội dung liên quan trực tiếp đến bài giảng, được giảng viên chỉ định và yêu cầu sinh viên phải sử dụng trong quá trình học. Nguồn học liệu là sự pha trộn giữa nguồn tin khoa học nội sinh của trường đại học và nguồn tin từ bên ngoài. Hệ thống nguồn học liệu của một ngành đào tạo, của bộ môn, khoa, trường - một bộ phận có giá trị đặc thù trong nguồn tin nội sinh của trường đại học phản ánh thương hiệu, uy tín của trường đại học.

Hiện nay, Trung tâm Thông tin - Thư viện Trường Đại học Tân Trào đã cơ bản đáp ứng được nhu cầu bạn đọc tại chỗ, tuy nhiên việc khai thác, sử dụng nguồn học liệu trên trang http://tttttv.daihoctantrao.edu.vn của Nhà trường còn hạn chế. Do vậy, để đáp ứng được nhu cầu bạn đọc một cách toàn diện, bài viết tập trung đi vào nội dung “Giải pháp khai thác nguồn học liệu phục vụ bạn đọc tại trường Đại học Tân Trào" nhằm hoàn thiện và nâng cao hiệu quả quản trị nguồn học liệu tại Trung tâm Thông tin - Thư viện Trường Đại học Tân Trào, góp phần giúp sự khai thác các nội dung của bạn đọc được hiệu quả và phong phú hơn.

2. Đánh giá thực trạng khai thác nguồn học liệu phục vụ bạn đọc tại trường Đại học Tân Trào hiện nay

Trung tâm Thông tin - Thư viện được thành lập theo Quyết định số 1512/QĐ-ĐHTTr của Hiệu trưởng 
Trường Đại học Tân Trào với chức năng nhiệm vụ phục vụ hoạt động giảng dạy, học tập, đào tạo, nghiên cứu khoa học, triển khai ứng dụng tiến bộ khoa học công nghệ và quản lý của Nhà trường thông qua việc sử dụng, khai thác các loại tài liệu có trong Thư viện. Trung tâm Thông tin - Thư viện là thành viên của Liên chi hội Thư viện đại học khu vực phía Bắc; Chi hội Thông tin - Thư viện Đại học, Cao đẳng khu vực Trung du miền núi phía Bắc. Nhà trường đã tăng cường bổ sung các giá sách theo tiêu chuẩn, trang bị các máy tính truy cập với đường truyền cao, nâng cấp chất lượng các phòng đọc sách, phòng tra cứu Internet, sách, giáo trình, tài liệu tham khảo. Thư viện quản lý các tài nguyên của trường bằng phần mềm ELIB-LRC. Hệ thống Cơ sở dữ liệu dùng chung luôn được khai thác có hiệu quả phục vụ cho học tập, nghiên cứu. Hàng năm, cán bộ, nhân viên Thư viện đều được Nhà trường cử đi tập huấn nghiệp vụ để nắm vững quy trình, kỹ năng nghiệp vụ $[4, \operatorname{tr} 62]$.

Tài liệu vật lý (Tài liệu truyền thống): Trung tâm Thông tin - Thư viện là nơi cung cấp tài liệu có nội dung chủ yếu tập trung vào các ngành học đang được đào tạo tại trường, do vậy, cán bộ, sinh viên tìm đến là các tài liệu vật lý như sách, báo, và tạp chí. Thư viện trường hiện đang quản lý 5.508 đầu sách, 180.855 bản sách; số lượng đề tài NCKH 126; luận án, luận văn là 105; số lượng bài báo đăng trên các tạp chí là 616 bài trong đó có 67 bài đăng trên các tạp chí khoa học quốc tế, 18 bài danh mục ISI [4, tr 63].

Đồng thời, đề cương mỗi môn học liệt kê các tài liệu tham khảo và thông tin chỉ dẫn cho việc khai thác các tài liệu này. Một trong những yêu cầu cơ bản đối với một đề cương môn học theo khung chương trình đào tạo là liệt kê các tài liệu tham khảo và thông tin thư mục chỉ dẫn giúp cán bộ, sinh viên có thể tìm kiếm và tiếp cận với các tài liệu đó. Hơn nữa, ngoài việc cung cấp phạm vi nội dung của học liệu tham khảo, danh sách này còn có khả năng định hướng cho người học trong việc chủ động tìm hiểu sâu hơn và rộng hơn nội dung họ cảm thấy hứng thú được đề cập đến trong môn học.

Tài liệu mở (trực tuyến): Nhờ việc liên kết với Trung tâm Học liệu và Công nghệ thông tin - Đại học Thái Nguyên, bạn đọc có nhiều điều kiện thuận lợi để truy cập các nguồn tài nguyên số đa dạng và đặc biệt là tính cập nhật rất cao. Theo số liệu thống kê, số cán bộ, giảng viên, sinh viên đến Trung tâm Thông tin - Thư viện tra cứu tài liệu, truy cập Internet trên thực tế trong
5 năm gần đây có sự tăng lên, một điểm tích cực cần được phát huy trong tiến trình phát triển của Trung tâm: Năm 2014 có 25.342 lượt bạn đọc; Năm 2015 có 34.768 lượt bạn đọc, lượt truy cập Internet 12.415 lượt; Năm 2016 có 38.348 lượt bạn đọc, lượt truy cập Internet 15.215 lượt; Năm 2017 có 36.524 lượt bạn đọc, lượt truy cập Internet 24.315 lượt; Năm 2018 có 34.125 lượt bạn đọc, lượt truy cập Internet 30.912 lượt [4, tr 64]. Các tài liệu số, từ việc mua quyền sở hữu, quyền truy cập, hoặc tham gia các mô hình liên kết chia sẻ dữ liệu của các cơ sở dữ liệu mang tính học thuật là điều quan trọng và được Nhà trường chú trọng triển khai. Việc số hóa này đã hỗ trợ cho việc lưu trữ tài liệu, cung cấp cho cán bộ, sinh viên nhiều sự lựa chọn hơn trong việc truy cập và khai thác.

Tuy vậy, trong quá trình khai thác và sử dụng nguồn học liệu tại Trung tâm Thông tin - Thư viện trường Đại học Tân trào cũng còn một số khó khăn, hạn chế như:

Tìm kiếm, lựa chọn thông tin: Thời đại công nghệ 4.0 đã đưa lại tính ưu việt là bạn đọc được cung cấp rất nhiều thông tin đa dạng, phong phú. Do vậy, bạn đọc cần phải tìm kiếm, lựa chọn những thông tin phù hợp, cập nhập cho hoạt động giảng dạy, nghiên cứu khoa học, học tập của mình. Thực tế tại trường Đại học Tân Trào chưa có nhiều các chương trình hoặc khóa đào tạo về kỹ năng khai thác hiệu quả kho tài nguyên hiện có của thư viện, phòng tư liệu hoặc các cơ sở dữ liệu đã đăng ký mua quyền truy cập [4, tr 63]. Đại đa số bạn đọc đều chưa được được trang bị những kỹ năng bài bản trong việc tìm kiếm thông tin phục vụ cho việc học tập và nghiên cứu khoa học.

Thu viện chua phát huy hết vai trò tu vấn và cung cấp các dịch vu thông tin cho cán bộ, sinh viên: Để có thể thực hiện đúng vai trò và trách nhiệm của mình trong một trường đại học, thư viện cần phải đáp ứng được nhiều tiêu chí khác nhau từ nguồn tài nguyên, trang thiết bị, nhân sự cho đến các sản phẩm và dịch vụ khai thác cung cấp thông tin.

Dịch vụ này ngoài việc cung cấp các thông tin học thuật phục vụ cho việc dạy và học còn phải có khả năng tư vấn và hỗ trợ cán bộ, sinh viên trong việc tìm kiếm và khai thác thông tin. Hơn nữa, dịch vụ này còn có vai trò trang bị kiến thức thông tin cho cán bộ, sinh viên bằng cách kết hợp với các đơn vị liên quan triển khai các chương trình đào tạo về kiến thức thông tin, kiến thức máy tính, kỹ năng tìm tin hoặc nhiều kiến thức và kỹ năng khác với mục đích giúp cán bộ, sinh viên có 
thể khai thác thông tin trong và ngoài thư viện một cách hiệu quả;

Thu viện chura có co sơ dĩ liệu tính phí: Hiện nay, trên giao diện trang http://tttttv.daihoctantrao.edu.vn của Trung tâm Thông tin Thư viện, trường Đại học Tân Trào, bạn đọc chủ yếu khai thác nguồn học liệu từ Trung tâm Học liệu và Công nghệ thông tin - Đại học Thái Nguyên, Trung tâm Thư viện - trường Đại học Hùng Vương, chưa có liên kết với các trang có cơ sở dữ liệu tính phí. Do đó, cán bộ, sinh viên ít có điều kiện tiếp cận với các cơ sở dữ liệu tính phí. Nếu bạn đọc được tiếp cận nhiều với cơ sở dữ liệu tính phí sẽ giúp bạn đọc có nhiều kỹ năng tìm kiếm thông tin, phát triển thêm kỹ năng đọc hiểu bằng tiếng nước ngoài.

3. Giải pháp khai thác nguồn học liệu phục vụ bạn đọc tại trường Đại học Tân Trào hiện nay

Để phát huy ưu điểm và khắc phục những khó khăn, hạn chế của Trung tâm Thông tin Thư viện Trường Đại học Tân Trào, bài báo đề xuất một số giải pháp như sau:

\subsection{Tham khảo hệ thống học liệu mở của Viện} Công nghệ Massachusetts (MIT)

Tại địa chỉ http://ocw.mit.edu/index.htm cho thấy hiện đang lưu trữ 2.260 tài liệu của các giáo trình dạng trực tuyến theo một ý tưởng rất giản lược là xuất bản mọi giáo trình hiện có của MIT duới hình thức trục tuyến để có thể đến được một cách rộng rãi với bất kỳ ai [5]. Hệ thống học liệu mở được hệ thống hóa theo chủ đề, mã số và theo khoa/ ngành đào tạo. Mỗi môn học đều có một hệ thống học liệu tương ứng và thực chất là một bộ cơ sở dữ liệu được liên kết với nhau. Chúng được giới thiệu theo một cấu trúc thống nhất tại trang chủ của mỗi môn học. Theo đó, các thông tin về người dạy, lịch trình giảng dạy, đối tượng sử dụng, các tài liệu, môn học có liên quan... được giới thiệu chi tiết và được kết nối tới các dữ liệu liên quan. Máy tìm được thiết kế tại Open Course Ware của MIT cho phép thực hiện các kiểu tìm: theo mã số môn học, chủ đề môn học, tên môn học và theo khoa/ngành hoc. Các nội dung chính của học liệu bao gồm: giáo trình của môn học, đề cương bài giảng của môn học, danh sách các tài liệu tham khảo, được tổ chức kết nối tới tài liệu/nguồn toàn văn - các loại bài tập, bài kiểm tra. Đáng chú ý là trong nhiều trường hợp, có công bố các bài giảng dưới dạng băng video.

\subsection{Liên kết với các nguồn học liệu khác/các co sủ̉ dũ liệu có tính phí}

Để liên kết với các nguồn học liệu khác thì Trung tâm Thông tin - Thư viện Trường Đại học Tân Trào cần nâng cấp, cải tiến giao diện trang website của Trung tâm để cập nhập, bổ sung thêm nguồn học liệu. Đồng thời, việc liên kết với các nguồn học liệu khác/các cơ sở dữ liệu có tính phí là một trong những hình thức hợp tác chia sẻ dữ liệu giúp cho nguồn học liệu phục vụ đào tạo trở nên đầy đủ và hoạt động hiệu quả hơn. Bởi nguồn tài nguyên của họ sẽ trở nên lớn hơn và giá trị sử dụng của nguồn tài nguyên thông tin cũng được nhân lên nhiều lần.

Một trong những hình thức liên kết hiệu quả và phổ biến là sự hợp tác, liên kết giữa các cơ quan thông tin thư viện của các trường đại học đặc biệt là các trường đại học có chung nhiều chuyên ngành đào tạo. Một hình thức khác cũng được nhiều cơ quan thông tin - thư viện tại các trường đại học phát huy đó là hình thức liên kết với nhiều cơ sở dữ liệu khoa học trên thế giới như ProQuest, EBSCO, Science Direct,... Với hình thức liên kết này, nguồn học liệu sẽ có điều kiện tốt nhất trong việc bao phủ phạm vi của các nguồn tin khoa học có uy tín trên thế giới.

\subsection{Luôn có các hình thức quảng bá để thu hút}

\section{ban đọ sủ dung}

Để cán bộ, giảng viên, sinh viên tìm đến với nguồn học liệu tại thư viện, các hình thức quảng bá sản phẩm và dịch vụ thông tin tại thư viện đại học cần được đẩy mạnh và phát huy. Việc quảng bá có hiệu quả phụ thuộc vào các ý tưởng của cán bộ thư viện. Ngoài ra, nguồn học liệu đa dạng, phong phú, kinh phí và các chính sách của thư viện đối với bạn đọc cũng giúp cho quá trình marketing quảng bá được thành công.

\section{Kết luận}

Việc khai thác nguồn học liệu phục vụ bạn đọc được xác định một nhiệm vụ quan trọng của Trung tâm Thông tin - Thư viện, Trường Đại học Tân Trào. Đó là sự phục vụ tốt nhất cho bạn đọc, đồng thời có ý nghĩa quảng bá rộng rãi giá trị của thư viện đại học. Do vậy, để xây dựng, khai thác nguồn học liệu phong phú, có giá trị, đáp ứng yêu cầu đào tạo, bồi dưỡng, phát triển nguồn nhân lực và phục vụ bạn đọc, cần chú trọng đến việc bổ sung tài liệu phù hợp với đề cương môn học, cung cấp tài liệu ở nhiều dạng khác nhau để bạn đọc có 
thể khai thác được nguồn thông tin được đầy đủ nhất. Ngoài ra, việc liên kết chia sẻ nguồn học liệu giữa các trung tâm thông tin - thư viện, trung tâm học liệu, các cơ sở có tính phí cần được đẩy mạnh, làm tăng số lượng và chất lượng nguồn học liệu tại thư viện, đáp ứng yêu cầu ngày càng cao của quản trị đại học.

\section{TÀI LIỆU THAM KHẢO}

1. Lê Quỳnh Chi (2015), Quản lý nguồn lục thông tin trong thu viện truò̀ng đại học, Luận án tiến sỹ khoa học giáo dục, Chuyên ngành: Quản lý giáo dục, Mã số: 621401 14- Tp. Hồ Chí Minh, Trường Đại học Su phạm Thành phố Hồ Chí Minh.

2. Nguyễn Huy Chương (2009), Nghiên cưu, thiết kê mô hình và xây dưng thử nghiệm nguồn học liệu trực tuyến phuc vu đào tạo chất luợng cao cho một số ngành, chuyên ngành tại Đại học Quốc gia Hà Nội, Đề tài cấp Đại học Quốc gia, Đại học quốc gia Hà Nội, Hà Nội.

3. Trần Thị Quý, Đỗ Văn Hùng, Phạm Tiến Toàn (2014), Quản trị nguồn học liệu số tại Truoòng Đại học Khoa học xã hội và Nhân văn, Đại học Quốc gia Hà Nội, Kỷ yếu Hội thảo khoa học Hoạt động thông tin thư viện với vấn đề đổi mới căn bản và toàn diện giáo dục đại học Việt Nam, Nxb Đại học Quốc gia Hà Nội, Hà Nội.

4. Trường Đại học Tân Trào (2019), Báo cáo đánh giá co sở giáo duc, tr 62-64.

5. https://ocw.mit.edu/index.htm, truy cập ngày 02/04/2020.

6. http://ttttv.daihoctantrao.edu.vn, truy cập ngày 02/04/2020.

\section{Solution to exploit learning resources for readers at Tan Trao University}

Le Kim Anh

Article info

Recieved:

9/4/2020

Accepted:

10/6/2020

Keywords:

Learning materials, exploi learning materials, solutions to exploit learning materials

\begin{abstract}
The system of learning resources is a valuable component in the endogenous information resources of the university, which reflect the brand and reputation of the university. For learning centers or information-library centers of higher education institutions, the library's learning resources, it provides a great support for your teaching, learning and scientific research activities. read. This article analyzes the situation and offers some solutions to exploit learning resources for readers at Tan Trao University.
\end{abstract}

